\title{
GESTÃO DEMOCRÁTICA E PROJETO POLÍTICO-PEDAGÓGICO: ESTUDO DE CASO EM UMA ESCOLA MUNICIPAL DE SÃO GONÇALO DOS CAMPOS/BA
}

\author{
http://dx.doi.org/10.5902/2318133816023
}

\author{
Raimunda Maria da Silva \\ Universidade Federal do Recôncavo da Bahia, Brasil. \\ Rodrigo da Silva Santos Cazumbá \\ Universidade Federal do Recôncavo da Bahia, Brasil.
}

\begin{abstract}
Resumo
Este trabalho discute-se acerca da gestão democrática e do projeto político-pedagógico, tendo como objetivo central analisar como ocorre o processo de construção coletiva do PPP em uma unidade de ensino. A pesquisa foi realizada em uma escola pública municipal de São Gonçalo dos Campos - BA, sendo desenvolvida por meio de um estudo de caso, com aplicação de questionários envolvendo professores, gestor e coordenador. $O$ trabalho constituiu-se de duas partes: a primeira consiste de uma revisão literária abordando os diversos aspectos da gestão democrática e projeto político-pedagógico. A segunda parte consiste na apresentação dos resultados de um estudo de caso. A pesquisa revelou que na escola estudada o PPP não é elaborado de forma coletiva e existe uma participação bastante limitada da comunidade escolar nos processos de gestão.

Palavras-chave: projeto político-pedagógico, gestão democrática, construção coletiva.
\end{abstract}

\section{DEMOCRATIC MANAGEMENT AND POLITICAL PEDAGOGICAL PROJECT: CASE STUDY ON A MUNICIPAL SCHOOL OF SÃO GONÇALO DOS CAMPOS/BA}

Abstract

This work aimed to make a discussion on Democratic and Political Pedagogical Project Management, with a main objective to analyze how the process of collective construction of PPP in a teaching unit occurs. The survey was conducted in a public school in São Gonçalo dos Campos BA, being developed through a case study with questionnaires involving teachers, manager and coordinator. The work is divided into two parts. The first consists of a literature review covering the various aspects of democratic management and Political Pedagogical Project. The second part consists of the presentation of the results of a case study. The survey revealed that at the school, the PPP is not drawn collectively and there is a very limited school community participation in the management process.

Key-words: political pedagogical project, democratic management, collective construction. 


\section{Introdução}

Aestão democrática na escola tem sido um assunto bastante discutido na 1 atualidade, visto ser um processo que oportuniza, tanto a participação das pessoas que fazem parte da escola, quanto das que estão a sua volta nas decisões administrativas. $O$ direito para que todos participem da gestão está garantido na legislação nacional, em especial na Lei de Diretrizes e Bases da Educação Nacional de 1996.

Existem vários elementos que contribuem para a consolidação da gestão democrática na escola, a exemplo do projeto político-pedagógico, que é um documento elaborado por todos os membros da comunidade escolar, sejam eles professores, gestores e comunidade local, com o propósito de organizar todo o trabalho da escola, tais como atividades administrativas, pedagógicas e didáticas.

Segundo Vasconcelos (2004, p. 169), o projeto político-pedagógico

é o plano global da instituição. Pode ser entendido como a sistematização, nunca definitiva, de um processo de planejamento participativo, que se aperfeiçoa e se concretiza na caminhada, que define claramente o tipo de ação educativa que se quer realizar. È um instrumento teórico metodológico para a intervenção e mudança da realidade. É um elemento de organização e integração da atividade prática da instituição neste processo de transformação.

A construção do projeto político-pedagógico, como método de planejamento, é essencial para o bom desenvolvimento das praticas educacionais, pois se sabe que é o PPP que define todas as ações pedagógicas e serve como referencial para guiar o trabalho dos profissionais da educação em uma determinada instituição.

Segundo Moacir Gadotti (1994, p.34), a elaboração do projeto político-pedagógico permite uma mudança de concepção sobre a escola pública, em que passa de "aparelho burocrático do Estado" para uma escola que reflete as conquistas da comunidade.

Diante desta realidade, o presente trabalho tem como objetivo principal analisar o processo de construção do projeto político-pedagógico de uma escola da rede municipal de São Gonçalo dos Campos - BA. Especificamente pretendemos verificar se a escola tem projeto político-pedagógico; conhecer em que medida os membros da comunidade escolar estão envolvidos na elaboração do projeto político-pedagógico e verificar se os professores utilizam o PPP como subsidio para o seu trabalho.

O trabalho compõe-se de duas partes: a primeira parte consiste em uma revisão de literatura que está organizada em capítulos. O primeiro capítulo aborda os aspectos políticos e pedagógicos da gestão democrática, o segundo traz algumas definições de projeto político-pedagógico, o terceiro aborda a construção coletiva do projeto políticopedagógico, e o quarto discute a relação entre PPP e currículo escolar. A segunda parte traz os resultados do estudo de caso realizado em uma escola municipal de São Gonçalo dos Campos - BA.

\section{Gestão democrática: aspectos políticos e pedagógicos}

A ideia de gestão participativa tem origem na Grécia antiga, com origem etimológica na palavra democracia que vem do grego antigo demos: povo e cratos: poder, e quer dizer que todos os sujeitos de determinada organização tem poderes para participar na 
tomada de decisões importantes. Luck (2010, p. 21) afirma que a participação pode ser caracterizada

pela força da atuação consciente pela qual os membros de uma unidade social reconhecem e assumem seu poder de exercer influência na determinação da dinâmica dessa unidade, de sua cultura e de seus resultados, poder esse resultante de sua competência e vontade de compreender, decidir e agir sobre questões que Ihes são afetas, dando-Ihe unidade, vigor e direcionamento firme.

Transformar a escola em uma instituição democrática é compartilhar as decisões, as conquistas e os fracassos; é integrar todos os membros da escola. Por muito tempo a participação da população nas decisões foi limitada, no entanto, isso não cabe mais nos dias atuais, visto que a gestão democrática pode ser considerada como um elemento fundamental para alcançar a qualidade da educação:

Tem-se como indicativo que para uma gestão democrática na escola é necessário um trabalho coletivo, o que não é meta fácil de atingir. A condução de processos que conduzam a um novo processo decisório responsável e comprometido neste trabalho coletivo, entendida como gestão democrática, poderá ser um dos caminhos para que a escola se insira num processo pedagógico eficiente orientado para a qualidade e eficácia da educação desejada para todos. (Rosenau, 2002, p. 7)

Os primeiros indícios da gestão democrática surgiram na década de 1980, época marcada por diversos movimentos em favor da redemocratização social, política e educacional. A partir desses movimentos começaram a surgir às bases legais para uma gestão voltada para os princípios de participação e autonomia (Gadotti, 1995).

A necessidade de uma administração democrática está expressa na Constituição de 1988 e consolidada na LDB, no art. 14, que explicita a gestão democrática, deixando claro que todos os segmentos da comunidade escolar devem estar envolvidos nas decisões e nas atividades de gestão escolar:

Art. 14 - Os sistemas de ensino definirão as normas da gestão democrática do ensino público na educação básica, de acordo com as suas peculiaridades e conforme os seguintes princípios: I participação dos profissionais da educação na elaboração do projeto pedagógico da escola; II. Participação das comunidade escolar e local em conselhos escolares ou equivalentes. Art. 15 - Os sistemas de ensino assegurarão às unidades escolares públicas de educação básica que os integram progressivos graus de autonomia pedagógica e administrativa e de gestão financeira, observadas as normas de direito financeiro público. (Brasil, 1996)

Mesmo com a Constituição de 1988 e a LDB vigorando, é implementado o Plano Nacional de Educação - lei n. 10.172, de 9 de janeiro de 2001 -, cujo foco é o trabalho coletivo, envolvendo todos os atores sociais, com o objetivo de construir a autonomia da escola, criando estratégias para promover a participação dos atores da comunidade escolar visando a melhoria da qualidade do processo ensino-aprendizagem no âmbito escolar. 
Fazer com que a escola se torne uma entidade democrática é um grande desafio, pois a escola ainda é vista como propriedade do governo ou do pessoal que nela trabalha. Sendo assim, é preciso que os gestores criem um ambiente estimulador da participação de todos os segmentos da comunidade escolar nas decisões importantes. Lück (1996) cita algumas ações principais que podem ser tomadas no sentido de promover essa participação:

a) Criar uma visão de conjunto associada a uma ação de cooperação. b) Promover um clima de confiança. c) Valorizar as capacidades e aptidões dos participantes. d) Associar esforços, quebrar arestas, eliminar divisões e integrar esforços. e) Estabelecer demanda de trabalho centrado nas idéias e não em pessoas. f) Desenvolver a pratica de assumir responsabilidades em conjunto. (p. 20)

Gadotti e Romão (1997) afirmam que a participação influencia na melhoria da qualidade de ensino, pois, por meio dela, todos os segmentos da comunidade podem compreender melhor o funcionamento da escola e conhecer com mais profundidade os que nela estudam e trabalham, intensificar seu envolvimento com ela e, assim, acompanhar melhor a educação ali oferecida.

\section{Conceituando o projeto político-pedagógico}

No sentido etimológico a palavra projeto vem do latim projectu, do verbo projicere, que significa se lançar para frente, portanto, a construção de um projeto políticopedagógico na escola significa a busca de mudanças e melhoria no processo de ensino e aprendizagem. Para Gadotti,

todo projeto supõe rupturas com o presente e promessas para o futuro. Projetar significa tentar quebrar um estado confortável para arriscar-se, atravessar um período de instabilidade e buscar uma nova estabilidade em função da promessa que cada projeto contém de estado melhor do que o presente. Um projeto educativo pode ser tomado como promessa frente a determinadas rupturas. As promessas tornam visíveis os campos de ação possível, compreendendo seus atores e autores. (1994, p. 579)

Ao fazer uma análise da relevância do PPP, Carvalho $(2004$, p. 156) relata que

o projeto político-pedagógico pode ser considerado como a carteira de identidade da escola, evidenciando os valores que cultua, bem como o percurso que pretende seguir em busca de atingir a intencionalidade educativa. Espera-se que prevaleça o propósito de oferecer a todos igualdade de oportunidades educacionais, 0 que não significa necessariamente, que as oportunidades sejam as mesmas e idênticas para todos.

O projeto político-pedagógico é o elemento que norteia todo o trabalho dos membros da escola. Nele devem estar contidas todas as metas e planejamento do que se pretende e o que deve ser feito para se chegar aonde se quer, buscando assim a construção de uma realidade sólida da educação. Segundo Vasconcelos (2004, p.169), o projeto político-pedagógico 
é o plano global da instituição. Pode ser entendido como a sistematização, nunca definitiva, de um processo de planejamento participativo, que se aperfeiçoa e se concretiza na caminhada, que define claramente o tipo de ação educativa que se quer realizar. $\grave{E}$ um instrumento teórico metodológico para a intervenção e mudança da realidade. É um elemento de organização e integração da atividade prática da instituição neste processo de transformação.

De acordo com Silva (2003),

o projeto político-pedagógico da escola pública, eixo ordenador e integrador do pensar e do fazer do trabalho educativo. Se concebido adequadamente,... revela quem é a comunidade escolar, quais são seus desafios com relação à boa formação, à conquista da autonomia e da gestão democrática, capaz esta de organizar, executar e avaliar o trabalho educativo de todos os sujeitos da escola... Eis o nosso desafio, recolocar o projeto político-pedagógico no centro de nossas discussões e práticas, concebendo-o como instrumento singular para a construção da gestão democrática. (p. 298)

O PPP não deve ser elaborado apenas para atender a uma exigência burocrática. $O$ mesmo é contínuo, pode ser reformulado quando necessário e, principalmente, não deve ser guardado e esquecido. É ferramenta fundamental a ser usada como guia das atividades pedagógicas, colocando em prática ações propostas, podendo a escola avaliar continuamente estas ações, e futuramente sanar as dificuldades encontradas no processo de ensino e aprendizagem.

\section{A construção coletiva do projeto político-pedagógico}

A construção coletiva do projeto político-pedagógico é fundamental para a democratização e conquista da autonomia da escola. Para Veiga (2009, p. 14),

a principal possibilidade de construção do projeto político-pedagógico passa pela relativa autonomia da escola, de sua capacidade de delinear sua própria identidade. Isto significa resgatar a escola como espaço público, lugar de debate, do diálogo, fundado na reflexão coletiva. Portanto, é preciso entender que o projeto político- pedagógico da escola dará indicações necessárias à organização do trabalho pedagógico, que inclui o trabalho do professor na dinâmica interna da sala de aula.

Ainda para a mesma autora, para que a construção coletiva do projeto políticopedagógico seja possível não é necessário convencer os professores, a equipe escolar e os funcionários a trabalhar mais, ou mobilizá-los de forma espontânea, mas sim propiciar oportunidades para que desenvolvam a capacidade de fazer e pensar o seu trabalho pedagógico de forma coerente (Veiga, 2009).

O projeto político-pedagógico, por ser o documento de natureza democrática, deve contar sempre com a participação dos docentes, gestores e comunidade escolar em geral na sua elaboração, desenvolvimento e aplicação, servindo de base para que a gestão democrática seja instaurada de fato na escola. Luck (2010, p. 21) afirma que a participação pode ser caracterizada 
pela força da atuação consciente pela qual os membros de uma unidade social reconhecem e assumem seu poder de exercer influência na determinação da dinâmica dessa unidade, de sua cultura e de seus resultados, poder esse resultante de sua competência e vontade de compreender, decidir e agir sobre questões que lhes são afetas, dando-lhe unidade, vigor e direcionamento firme.

O PPP ao ser construído e administrado de forma correta e participativa pode ajudar de forma decisiva a escola a alcançar seus propósitos, gerando troca de conhecimentos e experiências, visando o bem comum, estimulação de debates, reflexões, organizando a escola no seu âmbito interno e externo.

Paro (2000) descreve como essencial a participação do gestor escolar no processo de construção do projeto político-pedagógico da escola, pois sua atuação pode ter implicações sobre a transformação social, dentro e fora da escola.

O gestor, com os demais integrantes da comunidade escolar, deve garantir que a criação do PPP seja democrática e que seja revisado anualmente, de acordo com as necessidades que possam surgir. Esta revisão é importante para analisar se esta criação está no rumo certo ou precisa ser modificada para que venha melhorar ainda mais o aprendizado do aluno.

Para Veiga (2002),

o projeto político-pedagógico está relacionado com a organização do trabalho pedagógico em dois níveis: na organização da escola como um todo e na organização da sala, incluindo sua relação com o contexto social imediato, procurando preservar a visão de totalidade. Nesta caminhada será importante ressaltar que o projeto político-pedagógico busca a organização do trabalho pedagógico e conquista da autonomia da escola. (p.14)

$\mathrm{Na}$ verdade, a proposta pedagógica é a forma pela qual a autonomia se exerce. E a proposta pedagógica não é uma norma, nem um documento ou formulário a ser preenchido. Não obedece a prazos formais nem deve seguir especificações padronizadas. Sua eficácia depende de conseguir por em prática um processo permanente de mobilidade de "corações e mentes" para alcançar objetivos compartilhados (PCN, 2008).

\section{O projeto político-pedagógico e o currículo escolar}

O currículo escolar e o PPP são documentos que expressam a realidade escolar. Estes são importantes meios de se propagar a gestão democrática, pois devem ser construídos e mantidos com a colaboração de toda a comunidade escolar, pais, alunos, professores, direção e funcionários da escola, para que assim a escola tenha conhecimento dos problemas da comunidade e a comunidade tenha conhecimento dos problemas ocorridos na escola.

Segundo Lima (2010) o currículo

é base fundamental do Projeto político-pedagógico, pois é a partir dele que se define o que, para que, como e quem a escola deve ensinar. Durante muito tempo ele foi entendido como instrução, ou meramente grade 
curricular que detalhava os conteúdos trabalhados, mas na realidade é muito mais que isso, pois abarca todos os acontecimentos que ocorrem na escola, sobretudo as atividades direcionadas pelos professores na escola. (p. 41)

O currículo é um importante elemento constitutivo da organização escolar, ele define e organiza todos os conteúdos pedagógicos da instituição, sempre respeitando a diversidade cultural e o bom rendimento dos estudantes.

Lunardi (2004) define currículo como um conjunto de atividades envolvendo diversos sujeitos com diferentes interesses, cada um com tarefas exclusivas. Conforme Saviani (2003), consideramos práticas curriculares como o conjunto de propostas emitidas pelo governo assim como por meio da leitura realizada destes discursos pela escola por meio de seus sujeitos.

O PPP é uma das formas de se solidificar o currículo, pois ele está relacionado a organização do trabalho pedagógico, que visa ao melhoramento da qualidade de ensino, organização esta que vai do relacionamento existente entre docente e discente até a relação entre escola e comunidade.

De acordo com a legislação nacional, o currículo precisa constituir-se de duas partes que devem ser integradas pelo projeto político-pedagógico. A primeira parte é a base nacional comum, que corresponde a todos os conteúdos exigidos em todos os currículos nacionais para que os alunos tenham a oportunidade de ter os conhecimentos mínimos necessários para a sua formação. A outra é a parte diversificada do currículo, que deve incluir conteúdos relacionados à realidade local, regional e cultural a qual a escola está inserida. Sendo assim, Lima (2010) considera que

o projeto político-pedagógico da instituição é que faz a integração entre a Base Nacional Comum e a Parte Diversificada do currículo abordando os diversos aspectos como a saúde, a sexualidade, a vida familiar e social, o meio ambiente, o trabalho, a ciência, a tecnologia, a cultura, e as linguagens, com as áreas de conhecimento: Língua Portuguesa, Matemática, Ciências, Geografia, História, Língua Estrangeira, Artes, Educação Física e Educação Religiosa. Por esse motivo, a proposta curricular deve ser planejada em conjunto com o Projeto políticopedagógico, buscando uma perspectiva de currículo interdisciplinar, visando à interdependência, a interação e a comunicação entre os saberes, o que proporciona a conexão do conhecimento entre as disciplinas.

A escola deve ser responsável pela construção de um currículo que valorize a diversidade cultural do aluno, respeitando seu modo de vida, culturas, personalidades e modo de olhar o mundo. Os conteúdos curriculares devem ser definidos no sentido de permitir que os alunos tragam suas experiências de vida adquiridas culturalmente no cotidiano e conhecimentos que devem ser valorizados e explorados. Segundo Moreira e Silva (1997, p. 28), "o currículo é um instrumento de produção e de política cultural, no qual os materiais existentes funcionam como matéria prima de criação e recriação e, sobretudo, de contestação e transgressão". 


\section{Caracterização da pesquisa}

O presente estudo, cujo objetivo foi analisar o processo de construção do projeto político-pedagógico de uma escola da rede municipal de São Gonçalo dos Campos - BA foi desenvolvido por meio da realização de um estudo de caso.

André (1986) enfatiza características do estudo de caso como estudos que partem de alguns pressupostos teóricos iniciais, buscando retratar a realidade de forma completa e profunda, utilizando uma variedade de fontes de informações coletadas em diferentes momentos em situações variadas, sendo que os relatos do estudo de caso utilizam uma linguagem e uma forma mais acessível do que os outros tipos de pesquisa. Diante disso, entendemos o estudo de caso como uma estratégia de pesquisa relevante no processo educativo.

A investigação teve base qualitativa, sendo realizada a partir de questionários com perguntas abertas, aplicadas a seis professores, um coordenador pedagógico e um gestor. Por questionário "entende-se um conjunto de questões que são respondidas por escrito pelo pesquisado" (Gil, 2002, p. 114). Sendo assim, a busca pelos dados começou com uma conversa informal com a direção para conhecer a estrutura da escola e em seguida foi feita a aplicação dos questionários.

A escola está localizada na zona urbana do município de São Gonçalo dos Campos. Foi fundada em 13 de junho de 1986, na gestão do prefeito Antonio Pires dos Santos. A instituição escolar é mantida pela Prefeitura Municipal de São Gonçalo dos Campos, pela Secretaria Municipal de Educação, e é responsável pela prestação de serviços educativos do maternal ao primeiro ano do ensino fundamental.

A estrutura física da unidade escolar é composta por seis salas de aula com mal estado de conservação, pouco iluminadas e quentes, uma secretaria, uma cozinha, dois banheiros, sendo um masculino e um feminino, uma pequena área de lazer. Como recursos tecnológicos a escola dispõe de: uma televisão, um DVD, dois aparelhos de som, máquinas de xerox e um projetor de multimídia.

A escola funciona apenas no turno matutino e conta com seis professores com nível superior e uma vasta experiência com o trabalho em sala de aula, um coordenador pedagógico, um gestor e quatro funcionários na função de serviços gerais.

\section{Resultados da pesquisa}

Para saber como ocorre o processo de gestão e participação coletiva na escola foram feitas uma série de questionamentos envolvendo diversos membros da comunidade escolar, com professores, gestor e coordenador.

O primeiro questionamento feito foi como o objetivo de saber se na escola existia um projeto político-pedagógico em funcionamento, sendo assim constatou-se que a escola possui um projeto político-pedagógico, no entanto o mesmo encontra-se desatualizado, o que pode comprometer as atividades pedagógicas da instituição:

"A escola possui sim um projeto político-pedagógico, só que ele encontra-se desatualizado, iremos reavalia-lo ainda este ano." (Gestor escolar).

"Temos Projeto Pedagógico, no entanto ele esta fora do contexto atual da escola." (Professor 2) 
A existência de um PPP é imprescindível para que a escola conquiste a sua autonomia, pois de acordo com Veiga (2009, p. 110) o projeto político-pedagógico é um instrumento que mostra o que vai ser feito, quando, de que maneira, por quem, para chegar aos resultados, ele implica na valorização da identidade da escola, dando responsabilidade a todos os seus agentes.

Em relação ao processo de elaboração do projeto político-pedagógico foi questionado se houve a participação dos professores. Na instituição não há a participação direta dos professores na construção do PPP. O mesmo é elaborado pelo gestor e coordenador e depois apresentado aos professores para que eles possam expressar suas opiniões e trazer contribuições:

"O projeto pedagógico foi elaborado pelo gestor e coordenador, os professores só deram sugestões." (Professor 1).

"O PPP nós é apresentado pronto para fazermos a aprovação e exposição de ideias." (Professor 3).

De acordo com Vasconcelos, o PPP pode

atribuir competências e habilidades a todos os sujeitos envolvidos no processo educativo, respeitando-se os limites de seus processos de desenvolvimento, a diversidade e a singularidade de suas possibilidades; Construir autonomia, espírito de cooperação, reciprocidade; Produzir conhecimentos e criar relações positivas e democráticas entre todos os segmentos envolvidos; Favorecer a transformação grupal através do respeito mútuo, do diálogo, da participação e engajamento; Garantir o acesso e permanência com sucesso a todos. (Vasconcelos, 2000, p. 169)

Foi perguntado se os professores utilizam o PPP como subsídio para o seu trabalho e verificou-se que a maioria dos professores não utiliza o projeto político-pedagógico para guiar suas atividades. Sendo assim verifica-se que o projeto da escola foi elaborado apenas para atender uma exigência burocrática e não para melhorar o processo educativo

Quanto à participação da comunidade na construção do projeto político-pedagógico, foi observado que a comunidade não participa da elaboração do PPP e não tem conhecimento do seu conteúdo.

Em relação às atividades em que a escola costuma envolver a comunidade, verificou-se que a participação não acontece de forma plena, pois, de acordo com as observações foi possível perceber que a comunidade não se envolve no processo de gestão escolar, havendo participação apenas em eventos, festejos e algumas vezes em reuniões de pais e mestres:

"A comunidade participa apenas de eventos comemorativos e reuniões de pais e mestres, às vezes." (Professor 4).

"A participação da comunidade só acontece em eventos, projetos ou em comemorações." (Professor 2). 
"Estão envolvidos em várias atividades, como festas, reuniões, culminância de projetos." (Coordenador pedagógico).

De acordo com Comer (1884), o envolvimento dos pais na escola é bastante positivo, pois mostra aos alunos a importância da aprendizagem e desempenho escolar, ajuda a reduzir conflitos da escola com os pais, melhorando ainda mais o ambiente escolar.

\section{Considerações finais}

A gestão participativa tem como objetivo principal assegurar a gestão democrática, promovendo a participação de todos os membros da instituição na tomada de decisões. Sendo assim, o projeto político-pedagógico pode assegurar a gestão democrática, pois se sabe que ele é um documento elaborado coletivamente.

Este trabalho oportunizou compreender a visão do gestor, coordenador e professores integrantes da comunidade escolar sobre a importância da gestão democrática e construção coletiva do projeto político-pedagógico, bem como nos possibilitou conhecer como ocorre o processo de participação da comunidade na escola.

Pela pesquisa foi possível constatar que a escola possui um PPP, no entanto, o mesmo encontra-se desatualizado e não corresponde ao perfil atual da instituição. Isso nos leva a compreensão de que a escola não se baseia no projeto político-pedagógico para a realização de suas atividades pedagógicas. A falta de um PPP atualizado pode gerar varias falhas no ensino, pois este é um instrumento que precisa estar sempre passando por revisões e atualizações, no sentido de se adequar a realidade da escola.

Outro aspecto relevante observado no trabalho foi à ausência dos professores na construção do projeto pedagógico, não atendendo a exigência da LDB que diz que os docentes deverão participar da elaboração da proposta pedagógica. Nesse sentido, é preciso que os professores procurem compreender o agir coletivo e participativo em favor da formação de uma gestão democrática, observando a importância do PPP para a qualidade do processo de ensino-aprendizagem dos alunos.

Ademais, foi possível observar que os professores não utilizam o PPP como documento norteador de sua prática pedagógica, evidenciando que estes não são gestores de sua própria prática. É importante que todos os docentes sigam o projeto pedagógico em sua totalidade, em todos os momentos de sua atuação na escola, para que assim se alcançassem os objetivos planejados neste documento.

Constatou-se, também, que a comunidade externa possui uma participação bastante limitada na escola, no que se refere a decisões acerca do processo de gestão e trabalho pedagógico, havendo participação apenas e festejos e reuniões de pais e mestres. Diante disso é preciso que o gestor e coordenador assumam a responsabilidade de realizar atividades que incentivem a participação dessa comunidade nos processos de gestão, pois se sabe que um trabalho realizado coletivamente oportuniza a troca de experiências e saberes. 


\section{Referências}

BRASIL. Lei n. 9.394, estabelece as diretrizes e bases da educação nacional. Brasília: DOU, 1996.

BUSS, Rosinete Bloemer Pickler. Gestão escolar: cadernos de estudos. Indaial: Asselvi, 2008.

COMER, James P. Home-school relationships as they affect the academic success of children. Education and Urban Society, n. 16, 1984, p. 323-337.

GADOTTI, Moacir. O projeto político-pedagógico na escola: na perspectiva de uma educação para a cidadania. Brasília: Cortez, 1994.

GADOTTI, Moacir. Escola cidadã. São Paulo: Cortez, 1995.

GADOTTI, Moacir. Pressupostos do projeto pedagógico. CONFERÊNCIA NACIONAL DE EDUCAÇÃO PARA TODOS, 1, 1994. Anais ... Brasília: MEC, 1994.

LUCK, Heloísa. A gestão participativa na escola. Rio de Janeiro. Vozes, 2010.

LUNARDI, Geovana Mendes. A função social da escolarização básica: reflexões sobre as práticas curriculares da escola. CONGRESSO LUSO-AFRO-BRASILEIRO DE CIÊNCIAS SOCIAIS, 8, 2004. Anais ... Coimbra: Universidade de Coimbra, 2004.

MOREIRA, Antônio Flávio; SILVA, Tomaz Tadeu (org.). Currículo, cultura e sociedade. São Paulo: Cortez, 1997.

PARO. Vitor Henrique. Gestão democrática da escola pública. São Paulo: Ática. 2000

ROSENAU, Claudete Romualda. Ação do gestor escolar: estudo de caso com o desenvolvimento de proposta pedagógica. Florianópolis: UFSC, 2002. 99f. Dissertação (mestrado em Engenharia de Produção). Universidade Federal de Santa Catarina.

SAVIANI, Dermeval. O choque teórico da politecnia. Revista Trabalho, Educação e Saúde, Rio de Janeiro, v. 1, n. 1, 2003, p. 131-152.

SILVA, Maria Abadia. Do projeto político do Banco Mundial: ao projeto político-pedagógico da escola pública brasileira. Cad. Cedes, Campinas, v. 3, n. 61, 2003, p. 283-301.

VASCONCELLOS, Celso Santos. Planejamento: projeto de ensino-aprendizagem e projeto politico-pedagógico. São Paulo: Libertad. 2000.

VASCONCELLOS, Celso Santos. Coordenação do trabalho pedagógico: do projeto político-pedagógico ao cotidiano da sala de aula. São Paulo: Libertad, 2004.

VASCONCELLOS, Celso Santos. Projeto político-pedagógico: educação superior. Campinas: Papirus, 2004.

VEIGA, Ilma Passos Alencastro. Projeto político-pedagógico da escola: uma construção possível. Campinas: Papirus, 2009.

Rodrigo da Silva Santos Cazumbá é estudante de Ciências Biológicas na Universidade Federal do Recôncavo da Bahia.

Endereço: Rua São Caetano, Bairro Santo Antônio, 24 - 44330-000 - São Gonçalo dos Campos - BA.

E-mail: cazumbarodrigo@hotmail.com. 
Raimunda Maria da Silva é licenciada em Pedagogia pela Universidade Federal do Recôncavo da Bahia. Professora de Educação Infantil e Ensino Fundamental I da rede pública municipal de São Gonçalo dos Campos - BA

Endereço: Rua São Caetano, Bairro Santo Antônio, 24 - 44330-000 - São Gonçalo dos Campos - BA.

E-mail: raimunda.silva01@hotmail.com

Recebido em 30 de outubro de 2014.

Aceito em 18 de março de 2015. 